\title{
Knowledge, Attitude and Practice about malaria in Maji District, Bench Maji Zone, Southwest Ethiopia
}

\section{Abraham Tamirat*, Mesfin Geremew, Fira Abamecha and Wadu Wollancho}

College of Public Health, Department of Health Education and Behavioural Science P.O.Box:378, Jimma, Ethiopia

${ }^{*}$ Corresponding author: Abraham Tamirat, College of Public Health, Department of Health Educat4ion and Behaviour al Science P.O.Box:378, Jimma, Ethiopia, Tel: 913241339; E-mail: abrishntamirat@gmail.com

Received date: July 03, 2016; Accepted date: July 10, 2016; Published date: July 31, 2016

Copyright: (c) 2016 Abraham Tamirat, et al. This is an open-access article distributed under the terms of the Creative Commons Attribution License, which permits unrestricted use, distribution, and reproduction in any medium, provided the original author and source are credited.

\begin{abstract}
Background: Poor or lack of insecticide treated net (ITN) use as malaria preventive behaviour is one of the obstacles for the success of malaria prevention and control program. Therefore, Current information on insecticide treated net use as malaria preventive behaviour and its predictors are vital for malaria prevention and control program.
\end{abstract}

Objective: To identify determinants of insecticide treated net use as malaria preventive behaviour among households in Maji district, Bench Maji Zone, Southwest Ethiopia.

Methodology: Community based cross-sectional quantitative study supplemented by qualitative study was conducted from March $\neg 15$ to 30/2015 in Maji district, Bench Maji Zone of South Nation and Nationality People Regional State (SNNPR). A total of 770 selected household heads were involved in the study. Data was collected through face to face interview technique by trained data collectors. Data was entered and analyzed using SPSS version 20.0 statistical package. Multiple logistic regressions analysis was used to identify the independent predictors of insecticide treated net use as malaria preventive behaviour. Odds ratio, with $95 \%$ confidence level and $\mathrm{P}<0.05$ were used to determine statistically significant association.

Result: A total of $770(91 \%)$ participants were actually involved in the study. Of the total study participants, $76.5 \%$ were males and $23.5 \%$ were females. Forty point eight percent, $40.8 \%$ of study participants were ITN users in night before data collection. Multiple logistic regression analysis showed that ITN use had association with ever had malaria: $\mathrm{OR}=5.94(0.545-0.64)$, Perceived susceptibility to malaria: $\mathrm{OR}=3.47(1.92-6.26)$, perceived benefit of using ITN: OR=1.06 (1.02-1.106) and knowledge on malaria: OR 3.25(1.6-6.2).

Conclusion and recommendation: This study had revealed that ITN use was low in Maji district. Existing efforts should be revised specifically for its effect on individual perception of ITN use. The research calls for the need to strength the health education and behaviour change activities.

Keywords: Insecticide; Malaria; Prevention; Treatment; Intervention; Sampling; Knowledge

\section{Introduction}

Malaria is a disease caused by protozoan parasites belonging to the genus Plasmodium. The four species of the parasite in human are $\mathrm{P}$. falciparum, P. vivax, P. malariae and P. ovale. Plasmodium falciparum and Plasmodium vivax account for more than $95 \%$ of cases of malaria in the world. P. falciparum is the cause for the severe form of the disease and most deaths due to malaria $[1,2]$.

Each year, malaria results in 300 to 500 million clinical cases globally; of which $90 \%$ occur in Sub Saharan Africa [3]. There is consensus that about 0.5 billion clinical attacks of malaria take place every year, including 2-3 million severe attacks. Ethiopia is a tropical country, more than three-quarter of the landmass (altitude $<2000 \mathrm{~m}$ ) of the country is malarious, and about $68 \%$ ( $>50$ million people) of the total population is residing in areas at risk of malaria infections. Malaria is the leading cause of health problem in the country. The plasmodium species that have epidemiological importance in Ethiopia are P. falciparum and P. vivax $[4,5]$.

Studies suggested that relevant preventive behaviour associated with other environmental measures needed for effective malaria prevention and control effort. Any anti-malaria practices depend particularly on the preventive behaviour of the affected population. People's knowledge and perception of malaria influence both prevention and treatment seeking behaviour s [6-10].

Earlier literatures focused on vector biology and the malaria parasites, the importance of human behaviour in malaria transmission has been largely overlooked. The vertically organized anti-malaria program that was conducted largely without reference to the behaviour and the belief systems of the affected populations [11]. This makes a shadow on contribution of human behaviour for malaria prevention and control programs.

The globally launched initiative Roll Back Malaria program relies mainly on insecticide-impregnated bed nets (ITNs) and combination drug therapy (CDT). The people who sleep under them must hang ITNs and they should impregnate in a timely manner, frequently at the 
user's expense. Failure to sustain this intervention would result in increased sickness and death due to exposure of relatively nonimmune people to new infection [12].

Today Ethiopia is implementing a range of malaria control interventions that aim to improving access and equity to preventive health services, which include selective vector control using insecticide treated nets (ITNs and LLITN) and indoor residual spraying (IRS) [13]. However, there is no evidence for success achieved in such programs for sustained change. Of major concern is whether people are committed to used bed nets and other malaria preventive measures. Pertaining to the malaria preventive behaviour, many questions remain unanswered including individual households reason behind utilizing bed net.

Recent studies in the country tried to assess knowledge and beliefs about malaria and practices, access, treatment, and use of preventive measures but studies on householders' perceptions are limited and not explored the underlying malaria problems of marginalized areas like Maji district. This will call for further research since malaria related perception varies not only among different cultures but also among individuals depending on their socioeconomic background.

\section{Methodology}

\section{Study setting and design}

Community based cross-sectional quantitative study supplemented by qualitative study was conducted from March 15 to 30, 2015 in Maji district.

Maji district is one of the nine districts of Bench Maji Zone (located $661 \mathrm{~km}$ away from the center of Ethiopia) of South Nation and Nationality People Region (SNNPR). The mean altitude of the district ranges $1500-1900 \mathrm{~mm}$ above sea level. The average annual temperature and rain fall range from $200 \mathrm{c}$ to $250 \mathrm{c}$ and $1500-1800 \mathrm{~mm}$ annum respectively.

Maji district has 13 health posts, 4 clinics, 2 nuclear health centers and one rural drug vendor. According to official health department report of 2015, malaria was reported as leading cause of health institution visit. Topographic feature, flora and the presence rainfall all over 13 months is favorable for the incidence of malaria in the district.

\section{Study participants}

All randomly selected households in Maji district were included. Household heads were used as study participants. Households resided in the study area for more than six month and respondents who could communicate were included.

\section{Sample size and sampling technique}

The sample size was determined using single population proportion formula, taking the following parameters: single population proportion $(\mathrm{P}=50 \%), \mathrm{P}$ which is proportion of households with malaria preventive behaviour, 95\% confidence interval and 5\% marginal error of the estimate was considered. This yields a sample of 384 . To ensure the design effect of multi-stage sampling technique $384 \times 2=768$ and maintaining $10 \%$ non-response rate, the final sample size became 845 .

For qualitative study, 13 key respondents were interviewed until saturation and redundancy of information occurred.
Within district; there are small administrative entities called kebeles. There were a total of twenty three kebeles in Maji district. Ten kebeles were selected randomly using list of kebeles as sampling frame. The numbers of study households from each selected kebele were determined by proportional to the number of households in the kebele. Finally, households were selected by simple random sampling technique using lists the household as sampling frame.

\section{Data collection}

Structured questionnaires were adapted from previous similar studies as per the local context $[14,15]$. The instrument was prepared in English, then translated to official and local language (Amharic) and finally back translated to English by different individuals to keep consistency. The instrument covered information on socio demographic status, knowledge on malaria, and perception on malaria and ITN use as malaria preventive behaviour $\mathrm{s}$.

Data was collected through face to face interview of household heads using Amharic version instrument. Fifteen trained diploma nurses were collected the data. Data collection took fifteen days. Five supervisors with BSc and masters holders in health sciences and principal investigator supervised the whole process of data collection.

For qualitative data, in depth interview guide was prepared for judgmentally selected household heads to collect information by exploring on malaria specific beliefs, ITN use and malaria perception. Qualitative respondents were not included in quantitative samples. They were health extension workers, health agents and kebele leaders. Individuals from six kebeles were involved on the in-depth interview. On average; single in-depth interview was took 45 minutes. The principal investigator conducted in-depth interview using tape recorder.

\section{Statistical data analysis}

After data collection, data entry will be done using EPI INFO version 3.5 statistical packages. Frequency output will be used to check missing values and outliers. Descriptive statistics and summary measures will be employed to the data and cleaning will be done using original code number. Using odds ratio (OR) with 95\% limit of confidence interval, the association of dependent and independent variables will be assessed and their degree of associations will be computed. Potential confounding variables will be controlled by using Multiple Logistic regression using SPSS version 16 statistical packages.

Qualitative data was transcribed in the original language of interview first word-by -word from the audio tapes and field notes. And then it was translated to English for analysis. Primary theme was produced through manual coding using pen of different colors. Then it was pooled into broader concepts to form main themes. Besides, quotes of participants that exemplify key concepts will be used directly during analysis. Finally, the result will be triangulated with that of the quantitative one.

\section{Data quality management}

Study questionnaires were adapted from previous similar studies as per the local context. The instrument was prepared in English first, then translated to Amharic, and finally back translated to English by different individuals to keep consistency. Training was given for qualified data collectors and supervisors. The entire process of data collection were assisted and guided by supportive and close 
Citation: Abraham Tamirat, Mesfin Geremew, Fira Abamecha and Wadu Wollancho (2016) Knowledge, Attitude and Practice about malaria in Maji District, Bench Maji Zone, Southwest Ethiopia . J Trop Dis 4: 217. doi:10.4172/2329-891X.1000217

Page 3 of 7

supervision. The collected data were checked frequently at the field by the supervisors for its completeness and consistency. Pretesting on 5\% of respondents outside the study area but of the similar background was done to for cultural sensitivity and clarity of the questionnaire.

\section{Ethical consideration}

The Ethical clearance was obtained from College of Public Health and Medical Science Research and Publication Committee of Jimma University. Formal letter was given to Bench Maji Zone health office and Maji district health offices. All respondents were asked for their willingness for participation in the study and informed verbal consent was obtained after confidentiality of the information assured. Questionnaire was labelled with questionnaire ID, not the respondents' name. Tape recorded data were deleted after transcription.

\section{Results}

\section{Socio demographic characteristics}

The overall response rate of this study was 770 (91\%). Out of 770 household head respondents, $589(76.5 \%)$ were males and $181(23.5 \%)$ were females. The mean age was 36.8 (SD of 12.3 years). Nearly half, $381(49.5 \%)$ of the respondents belonged to Orthodox religion. The highest proportion of ethnic groups Amhara were; 243 (31.6\%). The literacy status showed that almost one third of the study participants $249(32.3 \%)$ were not able to read and write. Total numbers of pregnant mothers and under children were 362 and 79 respectively. The median household size was 4 as shown in Table 1.

\begin{tabular}{|c|c|c|}
\hline Variables $(n=770)$ & $\begin{array}{l}\text { Number } \\
\text { REQUENCY }\end{array}$ & $\%$ \\
\hline \multicolumn{3}{|l|}{ Sex } \\
\hline Males & 589 & 76.5 \\
\hline Female & 181 & 23.5 \\
\hline \multicolumn{3}{|l|}{ Place of living } \\
\hline Urban & 229 & 29.7 \\
\hline Rural & 541 & 70.3 \\
\hline \multicolumn{3}{|l|}{ Religion } \\
\hline Orthodox & 381 & 49.5 \\
\hline Protestant & 272 & 35.3 \\
\hline Muslim & 93 & 12.1 \\
\hline Catholic & 20 & 2.6 \\
\hline Other & 4 & .5 \\
\hline \multicolumn{3}{|l|}{ Ethnicity } \\
\hline Amhara & 243 & 31.6 \\
\hline Sheko & 213 & 27.7 \\
\hline Kaffa & 95 & 12.3 \\
\hline Bench & 82 & 10.6 \\
\hline Tigre & 59 & 7.7 \\
\hline
\end{tabular}

\begin{tabular}{|l|l|l|}
\hline Oromo & 57 & 7.4 \\
\hline Other & 21 & 2.7 \\
\hline Educational status & & \\
\hline Can't read \& write & 249 & 32.3 \\
\hline Read and write only & 182 & 23.6 \\
\hline Grade 1-4 & 116 & 15.1 \\
\hline Grade 5-10 & 178 & 23.1 \\
\hline Grade 11-12 & 26 & 3.4 \\
\hline $10+1$ up to 10+3 & 16 & 2.1 \\
\hline Diploma and above & 3 & .4 \\
\hline Have separate bedroom & & 80 \\
\hline Yes & 616 & 20 \\
\hline No & 154 & \\
\hline
\end{tabular}

Table 1: Socio demographic status of households in Maji district, SNNPRGS, March 2015.

\section{Knowledge, attitude and practice about malaria}

The participants' level of knowledge was grouped as low, moderate and high level with $(72.2 \%), 17.7 \%$ and $10.1 \%$ proportions of participants respectively. More than three fourth, 597(77.9\%) of household heads recognized the cause of malaria. Living in areas near to stagnant water and drinking dirty water were mentioned as sole cause of malaria by 227 (37.8\%), 120(20\%) of study participants respectively.

Similar finding was observed from in-depth interview, almost all participants knew malaria by its Amharic name "Weba". Climate was the most cited cause of malaria by the respondents. The presence of swampy area conducive for "Binbi" (type of mosquito) breeding, "Gudat" (hunger and being affected by other illness), 'were mentioned as the causes of malaria.

Large proportion 234 (45.7\%) of study participant were stated that under five children are risk group to get malaria (Table 2). Malaria symptoms were known by $86.1 \%$ of respondent, Fever, shivering, headache, loss of appetite, thirsty was mentioned by almost all of indepth interview participant. Body weakness, dizziness, vomiting and weight loss were among rarely mentioned symptoms. This finding also supported by "if my child experiences headache and shiver, the first disease I am going to suspect is malaria" Female, age 34 in-depth interview participant at Haro kebele.

About 384 (49.8\%) of respondents consider malaria as a transmitted disease. Among ways of transmission, stagnant water was cited by large proportion $175(22.7 \%)$. As to its treatment, 662(88.5\%) of respondent consider malaria as a disease which can be treated. In qualitative study half of participants were considered malaria as transmitted disease, there was also a difference in perceived ways of its transmission such as wearing cloth, drinking water using glass which was previously used by malaria patient. However, only $22 \%$ of study participants were cited mosquito bites as ways of transmission. All of in-depth interview participants knew malaria is a disease that can be treated. 
The great majority of the respondent feels Malaria as the most health problem $717(93.1 \%)$. In the majority of the malaria cases (81.8\%), help was sought. Among those, approximately (35.1\%) looked after help within one day. Almost all the respondents (96.5\%) said that their family member suffering from malaria sought modern treatment at a public health care facility.

\section{Perceived susceptibility of malaria}

We used nine items to assess perceived susceptibility of malaria, maximum and minimum scores were 14 and 45 with mean of 30.5 . Nearly half; 368 (52.1\%) of study participants had perceived susceptibility to malaria score above mean and 402 (47.8\%) of study participants were scored below mean.

In in-depth interview; more than three fourth of the participants perceived that they might get malaria. They mentioned conditions that increase susceptibility to malaria were presence of stagnant water, living near swampy area, lack of bed net in their home, poor personal and environmental hygiene, and journey to malarious area and being hungry. Moreover, the following opinion may support this. “... I think I am susceptible to malaria, due to my working nature, I always make a journey to low land areas." (32 years, male house hold head at Tum kebele).

\section{Perceived seriousness of malaria}

Seven items were used to assess perceived seriousness of malaria. Minimum and maximum score of this construct were 16 and 35 with mean and standard deviation of $18.94+4.27$. About $53.4 \%$ of study participants were scored above the mean and the remained $46.6 \%$ scored below the mean.

In our in-depth interview, all participants ranked malaria as a leading health problem. Risks attributed to malaria were death, illness, absenteeism from work, collapse of family life, consumption of time and money. "Malaria is dangerous disease, if treatment were not obtained, it can cause death, it can disturb work. "( 25 years old, male household head at Gobi kebele said it to explain the seriousness of the problem).

\section{Perceived benefit and barriers to using ITN}

Perceived benefits of taking malaria preventive actions were assessed using 7 items, it had mean of 20.49 with standard deviation of 4.50. About $57.1 \%$ of study participants had score above mean and $42.9 \%$ of study participants were scored less than the mean score. Perceived barrier of malaria preventive actions had a mean of 16.94 with standard deviation of 4.75 . About $55.8 \%$ of study participants had score above the mean and $44.2 \%$ were scored below the mean.

In in-depth interview we had explored perceived benefits of ITN; these were protection from mosquito bite, prevention of malaria and against other bugs. In addition, they also think ITN is more effective form than IRS. In addition participants were reported reasons why people do not use were unavailability, warm weather and daily mounting, use of ITN for other purpose (as curtain, scarf and cover of table) and suspicion of its effectiveness. It was supported by "it [ITN] has a lot of advantages: it make us free from malaria, it can also kill binbi (mosquito), I had ITN before but know it is out of use (Male, age 27, at Balt kebele).

Almost all in-depth interview participants accept benefit of early treatment such as saving life and preventing further complication.
Economic problems and distance from health facility are among the commonly reported reasons for delay to medical care seeking. Some hesitate to go to health facility early hoping they would get better. Thirty years old male in-depth interview participant from Bergi kebele said that, "When my child manifest symptoms of malaria, I rushed to go health center for treatment because it might result in sever complication ".

Some different opinions also identified during in-depth interview "I have "Agober" means (ITN) in my house but I don't want to use it because it can't make any difference, most of "Agober"s in our homes are not good, even they have no power to kill flies, I had observed when a lot of flies were running on them, Can it kill mosquito?". (41 Years in-male, at Kushit kebele).

Female in depth interview participant from Fajika kebele said that "My ITN was worn out before one year but still I am sleeping on it even though it may not be effective" (Female, age 34 at Mehal Maji Kebele).

\section{Malaria source of information}

Of the total, 527 (68.4\%) study participants were reported that as they got message concerning malaria. Large proportion 319 (60.9\%) of them considered radio as credible source of information. About 376 (4.8\%) of respondents were reported that at least one of their family member had ever got malaria. Among the total household heads 397 $(51.5 \%)$ of them reported that they had ever got malaria in their life history.

\section{ITN use as malaria preventive behaviours}

A total of 344 (44.27\%) of household's were using ITN at night before the date of data collection of which 310 (90.4\%) were properly hanged it. Among ITN users under five children, husband and wife accounts the large proportion; $43.6 \%$ and $43.8 \%$ respectively. Underfive children and pregnant mothers utilization rate of ITN was $40.33 \%$ and $36.7 \%$.

According to respondents report, malaria like illness were reported from 144 (18.7\%) households in last two weeks preceding to the date of data collection, they reported that at least one of their family members was manifested the symptom of malaria.

\section{Determinants of KAP}

Multivariate analysis were done for selected socio demographic factors, knowledge, perception and source information of respondents with reported use of at least one of their ITNs by household's at night before data collection. Variables which remain to have significant association were ever history of malaria infection with in family member, relatively higher perception on malaria susceptibility, relatively higher perceived benefit, and malaria knowledge.

Household head who ever get message about malaria more likely use ITN than other almost five times more likely to use ITN $(\mathrm{AOR}=5.94,95 \% \mathrm{CI}(0.545-.64)$. Household head who ever get malaria more likely use ITN than who hadn't infected $(\mathrm{OR}=1.34$, 95\% CI (1.21-1.54) and three times likely use ITN after adjustment for other variables $(\mathrm{AOR}=1.363,95 \% \mathrm{CI}(0.15-.86)$. Household head who had relatively higher perceived susceptibility malaria 1.69 times likely use ITN than those having relatively lower $(\mathrm{OR}=1.69,95 \% \mathrm{CI}(1.42-2.01)$ and 3 times more likely use ITN after adjustment for other variables $(\mathrm{AOR}=3.47,95 \% \mathrm{CI}(1.92-6.26))$. 
Citation: Abraham Tamirat, Mesfin Geremew, Fira Abamecha and Wadu Wollancho (2016) Knowledge, Attitude and Practice about malaria in Maji District, Bench Maji Zone, Southwest Ethiopia . J Trop Dis 4: 217. doi:10.4172/2329-891X.1000217

Page 5 of 7

Household heads who had relatively higher perceived benefit of malaria preventive actions nearly two times more likely use ITN $(\mathrm{OR}=1.766,95 \% \mathrm{CI}(1.455-2.144)$ and 1.06 times after adjustment for other variables $(\mathrm{AOR}=1.06,95 \% \mathrm{CI},(1.023-1.106)$. Having higher level malaria knowledge will increase likelihood of ITN utilization by tenfold than having level of knowledge $(\mathrm{OR}=10.15,95 \% \mathrm{CI}$
(5.244-19.127) and 3 times more likely use after adjustment for other variables $(\mathrm{AOR}=3.25,95 \% \mathrm{CI}(1.6-6.2)$. Having moderate level malaria knowledge increase ITN utilization by two times $(\mathrm{OR}=2.49,95 \% \mathrm{CI}$ (2.49-3.89) and 2 times after adjustment for other variables $(\mathrm{AOR}=2.34,95 \% \mathrm{CI}(1.2-4.3))$ as shown in Table 2.

\begin{tabular}{|c|c|c|c|c|c|}
\hline \multirow[t]{2}{*}{$\mathbf{S} / \mathbf{N}$} & \multirow[t]{2}{*}{ Variables } & \multicolumn{2}{|l|}{ IRS spray } & \multirow[t]{2}{*}{ Crude OR(95\%Cl) } & \multirow[t]{2}{*}{ Adjusted OR(95\%Cl) } \\
\hline & & Yes & No & & \\
\hline \multirow[t]{3}{*}{1} & Sex & & & & \\
\hline & Male & $217(47.9 \%)$ & $225(52.1 \%)$ & $1.02(0.94-1.18)$ & \\
\hline & Female & $47(44.4 \%)$ & $59(55.7 \%)$ & 1 & \\
\hline \multirow[t]{3}{*}{2} & Is there separated bed room? & & & & \\
\hline & Yes & $211(52.1 \%)$ & $194(47.9 \%)$ & $1.26(1.104-.340)^{*}$ & $2.33(1.34-4.13)^{*}$ \\
\hline & No & $43(32.3 \%)$ & $90(67.9 \%)$ & 1 & 1 \\
\hline \multirow[t]{3}{*}{3} & Total family size & & & & \\
\hline & $>4$ & $82(48.8 \%)$ & $87(51.2 \%)$ & 1 & 1 \\
\hline & $<4$ & $172(46.6 \%)$ & $197(53.4 \%)$ & $1.062(.825-1.36)$ & $0.908(0.56-1.48)$ \\
\hline \multirow[t]{3}{*}{4} & Type of house & & & & \\
\hline & Corrugated Iron sheet & $100(41.1 \%)$ & $142(48 \%)$ & 1 & 1 \\
\hline & Grass roof & $154(52 \%)$ & $142(48 \%)$ & $1.025(1.15-1.76)^{*}$ & $2.168(1,267-.708)^{\star}$ \\
\hline \multirow[t]{3}{*}{5} & Ever get message on malaria & & & & \\
\hline & Yes & $56(31.8 \%)$ & $121(68.2 \%)$ & $1.35(1.20-1.525)^{\star}$ & $2.50(1.314-3.854)^{\star}$ \\
\hline & No & $198(54.8)$ & $163(45.2 \%)$ & 1 & 1 \\
\hline \multirow[t]{3}{*}{6} & $\begin{array}{l}\text { Have ever your family member get } \\
\text { malaria? }\end{array}$ & & & & \\
\hline & Yes & $175(63.3 \%)$ & $103(36.6 \%)$ & $.920(1.609-2.29)^{*}$ & $1.02(0.52-2.016)$ \\
\hline & No & $79(30.4 \%)$ & $181(69.6 \%)$ & 1 & 1 \\
\hline \multirow[t]{3}{*}{7} & Perceived susceptibility & & & & \\
\hline & Above mean score & $82(38.5 \%)$ & $131(1.5 \%)$ & $1.25(1.096-1.442)^{\star}$ & $2.014(0.314-2.19)$ \\
\hline & Below mean score & $172(52.9 \%)$ & $153(47.1 \%)$ & 1 & 1 \\
\hline \multirow[t]{3}{*}{8} & Perceived benefit & & & & \\
\hline & Above mean score & $55(34.2 \%)$ & $106(65.8 \%)$ & $1.25(1.19-1.39)^{*}$ & $1.19(0.96-1.07)$ \\
\hline & Below mean score & $199(52.8 \%)$ & $178(47.2 \%)$ & 1 & 1 \\
\hline \multirow[t]{4}{*}{9} & Knowledge level & & & & \\
\hline & Low & $46(36.2 \%)$ & $81(63.8 \%)$ & 1 & 1 \\
\hline & Moderate & $125(49.2 \%)$ & $133(51.6 \%)$ & $1.262(0.845-1.884)$ & $0.59(0.3-1.19)$ \\
\hline & High level & $84(54.2 \%)$ & $70(45.6 \%)$ & $2.088(1.29-3.380)^{*}$ & $0.75(0.9-1.04)$ \\
\hline
\end{tabular}

Table 2: Comparison of IRS spray by selected variables of respondents, Maji district SNNPR, March 2015. 


\section{Discussion}

This study was conducted with the objective of assessing ITN utilization and its determinant factor affecting the utilization of ITN in the district.

In this study, it was learnt that $40.8 \%$ study participants had used ITN before data collection period. Concerning proper utilization of ITN, it was lower than the study result of malaria prone areas of Ethiopia (utilization of 81.6\%) and NET MARK survey of Amhara and Oromiya $65 \%[16,17]$. This discrepancy might be due to level of awareness and urbanization since most of our study participants were illiterate and live in rural and remote area. But our finding was consistence with study result of Uganda 45.5\% [18].

Households who have male heads were utilize ITN in large proportion when they compares to households lead by female heads $45.4 \%$ and $23.3 \%$ respectively with statistical significance. Our result is similar with study of Arbamich, Ethiopia, in which female household heads less likely utilized ITN than male household heads [19]. This difference might be educational and income possession. This implies households with female heads are disadvantaged in ITN utilization. Intervention messages have to be segmented for female households.

Getting message about malaria and not getting it had it is statistical significant difference. This implies malaria education activities can show difference in ITN use, exposing households to malaria related message specially message can help households to use ITN.

Regarding specific beliefs, people who used nets were more likely to believe that malaria is transmitted by mosquitoes and could be cured by modern medicine [20]. Our study revealed that holding higher perceived benefit of malaria preventive action, increase the chance of ITN use than lower perceived benefit, it implies that people's utilization of ITN can be enhanced through understanding benefit of bed net; during distribution of ITN it is critical to inform peoples about the benefit.

This study also revealed that $40.33 \%$ of under five children were slept under ITNs in the night previous to the data collection which was less when compared to study of wonago district, Ethiopia, which was $58 \%[21]$.

An African survey done in 12 malaria endemic countries in Africa reported that about $55 \%$ of under 5 children use nets and study done in western Kenya, $65.9 \%$ of under-five children slept under ITN in the previous night [22-25]. The reason may be priority was not given for under five, so that a child slept with his/her elderly might not get a chance to use an ITN.

Our result revealed that about $46.6 \%$ and $36.4 \%$ of participants think malaria was dangerous and killer disease which is not similar to study in Uganda which was about $98 \%$ and $95 \%$ of participants believed that malaria was dangerous and could cause death respectively. Of total the total $94 \%$ of study participants were ever heard of malaria; this result is consistent with study finding of Uganda $99 \%$ of study participants ever heard of malaria [3]. About $77.9 \%$ of our study participant knew the cause of malaria, and only $11 \%$ attributed the sole cause malaria to mosquito bite. It is lower than study result of, elsewhere in Zimbabwe and Wonago in which 55\%and $42.3 \%$ of participants able to mention mosquito as main cause of malaria $[14,21,26]$. The difference might be in the level of knowledge and socioeconomic factors among the study group. In Ethiopia, knowledge about malaria transmission has ranged from 17.3 to $63 \%$ $[10,27]$.
Only $22 \%$ of our study participant attributes mosquito as a cause of malaria, in in-depth interview we understand that participants knew from which place mosquito possible comes but they consider breeding sites as cause of malaria, this might indicate health education activities were ignored the importance covering exact cause of malaria. Studies had showed that knowledge about the malaria vector can reduce risk of infection. This is very critical issue in malaria prevention and control effort, a study in Zimbabwe concluded that there is a significant relationship between people's knowledge of the causes of malaria and their preventative measures taken against it [26].

This study revealed that ITN use significantly associated with perceived susceptibility of malaria, perceived benefit, ever history of malaria infection with in household heads and family members and level of malaria knowledge adjustment which is similar to that of the previous study [28].

To sum, the study Malaria knowledge has shown to be an important factor for prevention practices. Specifically the knowledge about malaria transmission and the use of ITN as a malaria prevention method should be strengthened. Less priority was given for malaria risk groups like children and pregnant mothers to sleep under ITN. This study had revealed that ITN use was low in Maji district. Existing efforts should be revised specifically for its effect on individual perception of ITN use. The research calls for the need to strength the health education and behaviour change activities.

\section{References}

1. World Malaria Report (2005) Geneva: WHO.

2. Brian M, Adams M, Brian M (1989) Clinical Tropical Diseases, 9th Blackwell Scientific ed.

3. Nahlen B, Clarc J, Alnwick D (2003) Insecticide treated mosquito nets. American Journal of Tropical Medicine and Hygiene $68: 1-5$

4. Schaller K (1972) Geometrical Monograph Series. Regional studies in Geographical Medicine.

5. Ashenafi W (2006) Changes in the spread of malaria in Ethiopia: case study from Awassa and Hossana area.

6. Comoro C, Nsimba SE, Warsame M, Tomson G (2003) Local understanding, perceptions and reported practices of mothers/guardians and health workers on childhood malaria in a Tanzanian district-implications for malaria control. Acta Tropical 87: 305-313.

7. Minja H, Schellenberg JA, Mukasa O, Nathan R, Abdulla S, et al. (2001) Introducing insecticide-treated nets in the Kilombero Valley, Tanzania: the relevance of local knowledge and practice for an information, education and communication (IEC) campaign. Tropical Medicine and International Health 6: 614-623.

8. Oberlander L, Elverdan B (2000) Malaria in the United Republic of Tanzania: cultural considerations and health-seeking behaviour. Bulletin of the World Health Organization 78: 1352-1354.

9. Shililu J, Ghebremeskel T, Seulu F, Mengistu (2003) Larval habitat diversity and ecology of Anopheline larvae in Eritrea. Med J Entomol 40: 921-929.

10. Kengeya JF, Seeley JA (1994) Kajura-Bajenja Recognition, treatment seeking behaviour and perception of cause of malaria among rural women in Uganda. Acta Trop: 267-273.

11. Iddrisu, Mumuni, Paolorossi (2008) Modern and traditional treatment of malaria and multi displinary and multi-cultural approach.

12. Kristina H, Veronica H, Ramila V (2003) Behavioural and social aspects of Malaria and its control. World Health Organization on behalf of the Special Program for Research and Training in Tropical Diseases.

13. Qualitative Study on Malaria Prevention and Control in Oromia and Amhara Regional States in Ethiopia (2009) Addis continental institute of public health 17:11-12. 
Citation: Abraham Tamirat, Mesfin Geremew, Fira Abamecha and Wadu Wollancho (2016) Knowledge, Attitude and Practice about malaria in Maji District, Bench Maji Zone, Southwest Ethiopia . J Trop Dis 4: 217. doi:10.4172/2329-891X.1000217

Page 7 of 7

14. Daddi J, Asefaw G, Hana B, Richard (2007) Malaria indicator survey Ethiopia: coverage and use of major malaria evention and control interventions. Malaria Journal 9: 58.

15. Mebratome B (2007) Assessment of insecticide mosquito net possession, utilization and associated factor determinant factors among pregnant women in Raya-Azebo district, Tigray regional state, north Ethiopia Addis Abeba Ethiopia.

16. Abebe A, Teshome GM Insecticide Treated Nets in Selected Malaria Prone Areas of Ethiopia, Ethiop. J Health Dev.

17. Net Mark Survey on Insecticide-Treated Nets (ITNs) in Ethiopia (2007).

18. Nuwaha F (2001) Factors influencing the use of bed nets in Mbarara municipality of Uganda. In Ame trop Med and Hygiene 65: 877-882.

19. Ayalew A, Amsalu F (2015) Utilization of insecticide treated nets in Arbaminch Town and the malarious villages of Arbaminch Zuria District, Southern Ethiopia.

20. Chukwuocha UM, Dozie INS, Onwuliri (2010) Perceptions on the Use of Insecticide Treated Nets in Parts of the Imo River Basin, Nigeria: Implications for Preventing Malaria in Pregnancy, African Journal of Reproductive Health Mar 14:11.

21. Gashaw D, Wagari D (2008) Knowledge and utilization of insecticide mosquito nets among freely supplied households in wonago woreda 22:34-41.

22. Alaii JA, Hawley WA, Kolczak MS (2003) Factors affecting use of permethrin-treated bed nets during a randomized control trial in western Kenya. American Journal of Tropical Medicine and Hygiene 68: 137-141.
23. Korenromp EL, Miller J, Cibuiskis RE, Cham MK, Alnwick D, et al. (2003) Monitoring mosquito net coverage for malaria control in Africa: Possession vs. use by children under 5 years. Tropical Medicine and International Health 8: 693-703.

24. Alaii JA, Hawley WA, Kolczak MS, Terkuile FO, Gimnig JE, et al. (2003) Phillips-Howard PA. Factors affecting use of permethrin-treated bed nets during a randomized control trial in western Kenya. American Journal of Tropical Medicine and Hygiene 68(4): 137-141.

25. Home based management of malaria/fever in Uganda strategy. A sociological analysis of acceptability, accessibility and compliance in Kumi and Kiboga districts (unpublished) WHO country Office, Uganda.

26. Vundule, Mharakurwa S (1996) Knowledge, Practices and perceptions about malaria in rural communities of Zimbabwe: relevance to malaria control. Bulletin of the World Health Organization 74 (1): 55-60

27. Kassahun N (2004) Ethiopia Roll Back Malaria Consultative Mission: Essential Actions to Support the Attainment of the Abuja Targets. Ethiopia RBM Country Consultative Mission Final Report.

28. Conner M, Norman P (2005) Predicting health behaviour: A social cognition approach. Predicting Health Behaviour: Research and practice with social cognition models. 